\title{
Treadmill exercise and wheel exercise improve motor function by suppressing apoptotic neuronal cell death in brain inflammation rats
}

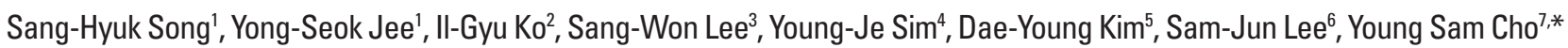 \\ 'Department of Physical Activity Design, Hanseo University, Seosan, Korea \\ ${ }^{2}$ Department of Physiology, College of Medicine, Kyung Hee University, Seoul, Korea \\ ${ }^{3}$ Department of Physical Education, Korea Military Academy, Seoul, Korea \\ ${ }^{4}$ Department of Physical Education, Kunsan National University, Gunsan, Korea \\ ${ }^{5}$ Department of Sports Healthcare, College of Humanities \& Social Sciences, Inje University, Gimhae, Korea \\ ${ }^{6}$ Department of Physical Education, College of Health, Welfare, and Education, Tong Myong University, Busan, Korea \\ ${ }^{7}$ Department of Urology, Kangbuk Samsung Hospital, Sungkyunkwan University School of Medicine, Seoul, Korea
}

Brain inflammation is involved in many brain disorders, such as brain ischemic injury, Alzheimer diseases, and Parkinson disease. Physical exercise has been recommended for the prevention and treatment of many brain inflammatory diseases. In the present study, the effects of exercise on motor function in relation with apoptotic neuronal cell death following neuroinflammation were investigated. Moreover, we compared the effect of forced exercise with voluntary exercise on neuroinflammation-induced motor malfunction. For this study, rota-rod test, vertical pole test, foot fault test, terminal deoxynucleotidyl transferasemediated dUTP nick end labeling (TUNEL) assay, immunohistochemistry for caspase-3, and western blot for Bcl-2 and Bax were performed.
Lipopolysaccharide was intraventricular infused for induction of brain inflammation. Treadmill exercise and wheel exercise were conducted during 6 weeks. In the present results, Treadmill exercise and wheel exercise alleviated brain inflammation-induced motor impairments by suppressing apoptotic neuronal cell death in the motor cortex. These effects of treadmill exercise and wheel exercise were similarly appeared.

Keywords: Treadmill exercise, Wheel exercise, Brain inflammation, Motor function, Apoptosis

\section{INTRODUCTION}

Inflammation is the part of the complex biological responses of various tissues to harmful stimuli, such as pathogens, damaged cells, or irritants. The inflammatory response is involved in many brain disorders, such as brain ischemic injury, Alzheimer diseases, and Parkinson disease (Emerit et al., 2004; Strosznajder et al., 2003). Neuroinflammation of brain is accompanied by neurodegeneration, including necrotic and apoptotic neuronal cell death (Trendelenburg, 2008). The previous studies indicated that neuroinflammation induced long-lasting cognitive impairment and motor dysfunction through activation of apoptotic process (Czapski et al., 2010; Jacewicz et al., 2009).

Apoptosis is a form of cell death that serves to eliminate dying cells in proliferating or differentiating cell populations, thus apoptosis plays a crucial role in normal development and tissue homeostasis (Woodle and Kulkarni, 1998). Nevertheless, inappropriate or excessive apoptosis has been implicated in diverse neurological disorders (Johnson et al., 1995; Lee et al., 2003). Terminal deoxynucleotidyl transferase-mediated dUTP nick end labeling (TUNEL) assay detects DNA fragmentation, one of the characteristics of apoptotic cell death (Gavrieli et al., 1992).
${ }^{*}$ Corresponding author: Young Sam Cho (iD https://orcid.org/0000-0002-2966-7971 Department of Urology, Kangbuk Samsung Hospital, Sungkyunkwan University School of Medicine, 29 Saemunan-ro, Jongno-gu, Seoul 03181, Korea Tel: +82-2-2001-2237, Fax: +82-2-2001-2247, E-mail: choys1011@naver.com Received: October 24, 2018 / Accepted: November 26, 2018
This is an Open Access article distributed under the terms of the Creative Commons Attribution Non-Commercial License (http://creativecommons.org/licenses/by-nc/4.0/) which permits unrestricted non-commercial use, distribution, and reproduction in any medium, provided the original work is properly cited. 
Activation of caspases is another important characteristic of apoptosis. Caspase-3 is a key executor of apoptosis (Cohen, 1997), in addition, $\mathrm{Bcl}-2$ family is implicated in regulation of apoptosis. The Bcl-2 family is classified into antiapoptotic proteins and pro-apoptotic proteins according to their functions, and then, the balance between pro-apoptotic members and anti-apoptotic members determines the mitochondrial response to apoptotic stimuli (Upadhyay et al., 2003).

Lipopolysaccharide (LPS) is a lipid-containing polysaccharide which is endotoxin and acts as an important group-specific antigen. It is also derived from the cell wall of gram-negative bacteria and induces immunoglobulin secretion. LPS has widely been used for the induction of inflammation in the peripheral and central nervous systems. Neuroinflammation induced by LPS showed excessive apoptotic neuronal cell death in the many brain areas (Czapski et al., 2007). LPS treatment also induced electrophysiological, metabolic, and morphological changes with a decrease in the numbers of neuronal cells in the cortex and hippocampus of rats (Czapski et al., 2010).

Physical exercise has been recommended for the prevention and treatment of many brain inflammatory diseases. Wheel running for 3 weeks reduced the expression of mRNAs of apoptosis-associated genes, such as the $\mathrm{Bcl}-2$ gene family and neuronal death protein DP5 (Tong et al., 2001). Parkinson patients had an increase in anti-inflammatory cytokines after regular exercise (Cadet et al., 2003). Increased blood flow caused by physical activity decreased local concentrations of inflammatory cytokines in the brain (Winkelman, 2004). Petersen and Pedersen (2005) reported that regular exercise exerted an anti-inflammatory effect through exercise-induced muscle release of interleukin (IL)-6, which increases anti-inflammatory proteins, such as IL-1 and IL-10, in the blood, as well as blocks production of tumor necrosis factor- $\alpha$. Regular voluntary exercise has been considered a therapeutic tool for brain injury induced by inflammation (Funk et al., 2011; Nichol et al., 2008).

In the present study, the effects of exercise on motor function in relation with apoptotic neuronal cell death following neuroinflammation were investigated. Moreover, we compared the effect of forced treadmill exercise with voluntary wheel exercise on neuroinflammation-induced motor malfunction. For this study, rota-rod test, vertical pole test, foot fault test, TUNEL assay, immunohistochemistry for caspase-3, and western blot for $\mathrm{Bcl}-2$ and Bax were performed.

\section{MATERIALS AND METHODS}

\section{Animals and grouping}

After purchasing male Sprague-Dawley rats, weighing 200 10 $\mathrm{g}$ (7 weeks old) from a commercial breeder (Orient Co., Seoul, Korea), the experimental procedures were performed in accordance with the animal care guidelines of the National Institutes of Health and the Korean Academy of Medical Sciences. The rats were classified into four groups ( $\mathrm{n}=10$ in each group): sham-operation group, brain inflammation-induced group, brain inflammation-induced and treadmill exercise group, brain inflammation-induced and wheel exercise group.

\section{Induction of brain inflammation}

Brain inflammation was induced, as described previously (Kim et al., 2013). Zoletil $50(10 \mathrm{mg} / \mathrm{kg}$, intraperitoneally; Vibac Laboratories, Carros, France) was used to anesthetize the rats. For the induction of brain inflammation, the rats were placed in a stereotaxic frame. Though a hole drilled in the skull, a 26-gauge needle was implanted into the intraventricle area at the following coordinates: $1.2 \mathrm{~mm}$ lateral to the midline, $0.9 \mathrm{~mm}$ anterior to the coronal suture, and depth $3.3 \mathrm{~mm}$ deep from the surface of brain. Seven $\mu \mathrm{L}$ of solution containing LPS (Sigma Chemical Co., St Louis, MO, USA) was infused over $3 \mathrm{~min}$. The needle remained in place for an additional 3 min after infusion and subsequently was withdrawn slowly. Opposite site was operated at the next day as the same procedure.

\section{Treadmill exercise protocol}

Treadmill running applied to the rats in the treadmill exercise group for $30 \mathrm{~min}$ per a day during 6 weeks. The running speed was $5 \mathrm{~m} / \mathrm{min}$ for $5 \mathrm{~min}, 8 \mathrm{~m} / \mathrm{min}$ for $5 \mathrm{~min}$, and then $10 \mathrm{~m} / \mathrm{min}$ for $20 \mathrm{~min}$, without inclination. The daily running distance was $265.00 \pm 0.00 \mathrm{~m}$.

\section{Wheel exercise protocol}

The rats in the wheel exercise group was housed in each rat cage containing plastic running wheels (diameter, $15 \mathrm{~cm}$ ) during 6 weeks. A magnet attached to a running wheel triggered a magnetic reed switch that input to an electrical counter. Revolution number was recorded between 6:00 p.m. and 9:00 a.m., as the rat ran almost exclusively during the dark period. Wheel revolutions were counted irrespective of the direction of the wheel and the number was converted to distance in meters per day. The daily running distance was $258.25 \pm 10.40$ that was similar with the 
treadmill running.

\section{Rota-rod test}

Rota-rod test was used to determine balance, as described previously (Jung and Kim, 2017). Rota-rod test was performed at 38 days after induction of brain inflammation. For this test, the rat was placed on the rod and then the rat ran while rod was rolling. At the starting, speed was set at $4.5 \mathrm{rpm}$, and then speed was increased from 4.5 to $8 \mathrm{rpm}$ within $5 \mathrm{~min}$. The trial ended if the rat fell off from the rung. An arbitrary time limit of $300 \mathrm{sec}$ was set for the testing procedure.

\section{Vertical pole test}

To assess the motor coordination, vertical pole test was performed, as described previously (Yun et al., 2014). The rat was trained in a vertical pole test at 39 days after induction of brain inflammation. The rat was placed on a cloth-tape-covered pole (diameter, $3.0 \mathrm{~cm}$; length, $150 \mathrm{~cm}$ ), then the pole was gradually lifted to a vertical position and the time a rat stayed on the pole was recorded for a maximum of $180 \mathrm{sec}$. The rats were habituated to the task in 2 trials per day during 2 days. On test day (third day), 3 measures were taken over 5 trials per rat.

\section{Foot fault test}

The foot fault score of the foot fault test was determined to evaluate walking ability at 41 days after induction brain inflammation, as described previously (Rodriguez et al., 2016). The rat was placed on an elevated, grid floor $(34 \mathrm{~mm} \times 29 \mathrm{~mm})$ for $2 \mathrm{~min}$. The openings in the grid were $3 \mathrm{~mm}^{2}$. While moving around on the grid, the rat typically placed their paws on the wire frame for foot holds. A foot-fault is counted when there is incorrect placement of an impaired forward limb which leads to a slip (called foot-fault). The number of foot fault for both fore- and hind-limb and the total number of forelimb step were recorded for each animal. A primary measure of interest was the percentage of contralateral forelimb foot faults per forelimb step minus the percentage ipsilateral forelimb foot faults per forelimb step. Foot fault score $(\%)=$ contralateral forelimb error/contralateral forelimb steps $\times 100$.

\section{Tissue preparation}

The rats were sacrificed one day after determining foot fault test (42 days after inducing brain inflammation). After anesthetizing by Zoletil 50 (10 mg/kg, intraperitoneally; Vibac Laboratories), $50 \mathrm{mM}$ phosphate-buffered saline was transcardially perfused, and fixed with a $4 \%$ paraformaldehyde in $100 \mathrm{mM}$ phosphate buffer
$(\mathrm{pH}, 7.4)$ solution. After dissecting, the brains were postfixed in the same fixative solution during overnight and then transferred into a $30 \%$ sucrose solution. Coronal sections with $40-\mu \mathrm{m}$ thickness were made by a freezing microtome (Leica, Nussloch, Germany). Ten slice sections on average in the motor cortex (M1) were collected from each rat. The sections of $2.70 \mathrm{~mm}$ to 1.00 $\mathrm{mm}$ posterior from the bregma were used for immunohistochemistry.

\section{Western blot analysis}

Bax and Bcl-2 expressions were detected by western blot analysis, as described previously (Shin et al., 2016). The tissues were homogenized with lysis buffer with $50 \mathrm{mM}$ Tris- $\mathrm{HCl}(\mathrm{pH} 8.0)$, $150 \mathrm{mM} \mathrm{NaCl}, 10 \%$ glycerol, $1 \%$ Triton X-100, $1.5 \mathrm{mM} \mathrm{MgCl}$. 6 $\mathrm{H}_{2} \mathrm{O}, 1 \mathrm{mM}$ EGTA, $1 \mathrm{mM}$ PMSF, $1 \mathrm{mM} \mathrm{Na}_{2} \mathrm{VO}_{4}$, and $100 \mathrm{mM}$ $\mathrm{NaF}$, and then centrifuged at 14,000 rpm during $30 \mathrm{~min}$. BioRad colorimetric protein assay kit (Bio-Rad, Hercules, CA, USA) was used to measure protein content. Protein with $30 \mu \mathrm{g}$ was separated on sodium dodecyl sulfate-polyacrylamide gels and transferred onto a nitrocellulose membrane. As primary antibodies, mouse beta-actin antibody (1:1,000; Santa Cruz Biotechnology, Santa Cruz, CA, USA), mouse Bcl-2 antibody (1:1,000; Santa Cruz Biotechnology), and rabbit Bax antibody (1:1,000; Santa Cruz Biotechnology) were used. Horseradish peroxidase-conjugated anti-mouse antibody for beta-actin and Bcl-2 (1:3,000; Vector Laboratories, Burlingame, CA, USA), and horseradish peroxidaseconjugated anti-rabbit antibody for Bax (1:3,000; Vector Laboratories) were used as secondary antibodies. Experiment was performed in normal lab conditions and at room temperature except membrane transfer. Membrane was transferred at $4^{\circ} \mathrm{C}$ with the cold pack and prechilled buffer. Enhanced chemiluminescence detection kit (Santa Cruz Biotechnology) was used for band detection.

\section{TUNEL assay}

Using In Situ Cell Death Detection Kit (Roche, Mannheim, Germany), TUNEL staining was performed, as described previously (Park et al., 2016). The sections were postfixed in ethanol-acetic acid (2:1) and rinsed. Then, the sections were treated with proteinase $\mathrm{K}(100 \mu \mathrm{g} / \mathrm{mL})$, rinsed, incubated in $3 \% \mathrm{H}_{2} \mathrm{O}_{2}$, permeabilized with $0.5 \%$ Triton $\mathrm{X}-100$, rinsed again, and treated in TUNEL reaction mixture. The sections were rinsed and visualized using Converter-POD with $0.03 \%$ 3,3'-diaminobenzidine (DAB). Nissls (DAKO, Glostrup, Denmark) was used for counter-staining, and the sections were finally mounted onto gela- 
tin-coated slides. After the slides were dried under the room conditions, Permount (Fisher Scientific, Fair Lawn, NJ, USA) was used for the coverslips mounting.

\section{Caspase- 3 immunohistochemistry}

Caspase-3 immunohistochemistry was performed, as described previously (Park et al., 2016). The sections were drawn from each brain and treated with mouse anti-caspase- 3 antibody (1:500; Santa Cruz Biotechnology) during overnight, and then treated with biotinylated mouse secondary antibody (1:200; Vector Laboratories) for another $1 \mathrm{hr}$. Bound secondary antibody was then amplified with Vector Elite ABC kit (1:100; Vector Laboratories). The antibody-biotin-avidin-peroxidase complexes were visualized using $0.03 \% \mathrm{DAB}$ and the sections were finally mounted onto gelatin-coated slides. After the slides were dried under the room conditions, Permount (Fisher Scientific) was used for the coverslips mounting.

\section{Data analysis}

To compare relative expressions of $\mathrm{Bcl}-2$ and Bax, detected bands were calculated densitometrically using Molecular Analyst version 1.4.1 (Bio-Rad). The cross-section area of muscle tissue from each slice was measured using Image-Pro Plus computer-assisted image analysis system (Media Cyberbetics Inc., Silver Spring, MD, USA) attached to a light microscope (Olympus, Tokyo, Japan). The numbers of TUNEL-positive and caspase-3-positive cells in the motor cortex were counted.

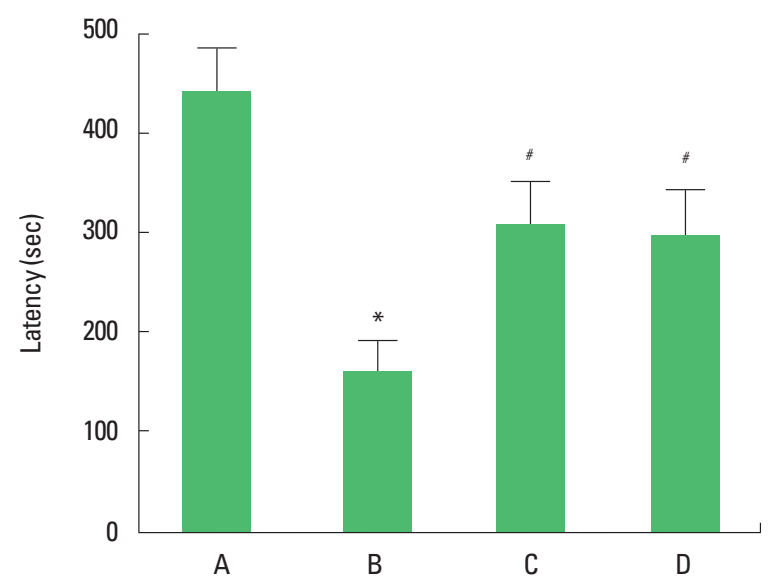

Fig. 1. Effects of treadmill exercise and wheel exercise on balance in the rota-rod test. A, sham-operation group; $\mathrm{B}$, brain inflammation-induced group; $\mathrm{C}$, brain inflammation-induced group and treadmill exercise group; $D$, brain inflammation-induced and wheel exercise group. ${ }^{*} P<0.05$ compared with sham-operation group. ${ }^{\sharp} P<0.05$ compared with brain inflammation-induced group.
Statistical analysis was performed using one-way analysis of variance followed by Duncan post hoc test, and the results are expressed as the mean \pm standard error of the mean. Significance was set as $P<0.05$.

\section{RESULTS}

\section{Rota-rod test}

The latency of the rota-rod test is presented in Fig. 1. The present results showed that latency in the rota-rod test was decreased in the brain inflammation-induced rats $(P<0.05)$, whereas, treadmill exercise and wheel exercise enhanced the latency in the brain inflammation-induced rats $(P<0.05)$. Treadmill exercise and wheel exercise exerted similar effect on latency in the rota-rod test.

\section{Vertical pole test}

The descending time of the vertical pole test is presented in Fig. 2. The present results showed that descending time in the vertical pole test was decreased in the brain inflammation-induced rats $(P<0.05)$, whereas, treadmill exercise and wheel exercise increased descending time in the brain inflammation-induced rats $(P<0.05)$. Treadmill exercise and wheel exercise exerted similar effect on descending time in the vertical pole test.

\section{Foot fault test}

The foot fault score of the foot fault test are presented in Fig. 3.

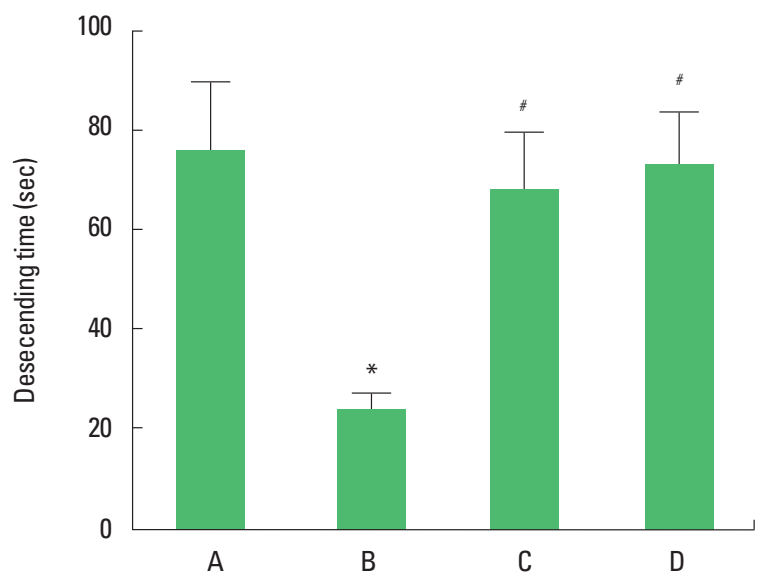

Fig. 2. Effects of treadmill exercise and wheel exercise on motor coordination in the vertical pole test. A, sham-operation group; B, brain inflammation-induced group; $C$, brain inflammation-induced group and treadmill exercise group; $D$, brain inflammation-induced and wheel exercise group. ${ }^{*} P<0.05$ compared with sham-operation group. ${ }^{\sharp} P<0.05$ compared with brain inflammation-induced group. 
The present results showed that foot fault score in the foot fault test was increased in the brain inflammation-induced rats $(P<0.05)$, whereas, treadmill exercise and wheel exercise suppressed latency in the brain inflammation-induced rats $(P<0.05)$. Treadmill exercise and wheel exercise exerted similar effect on descending time in the foot fault test.

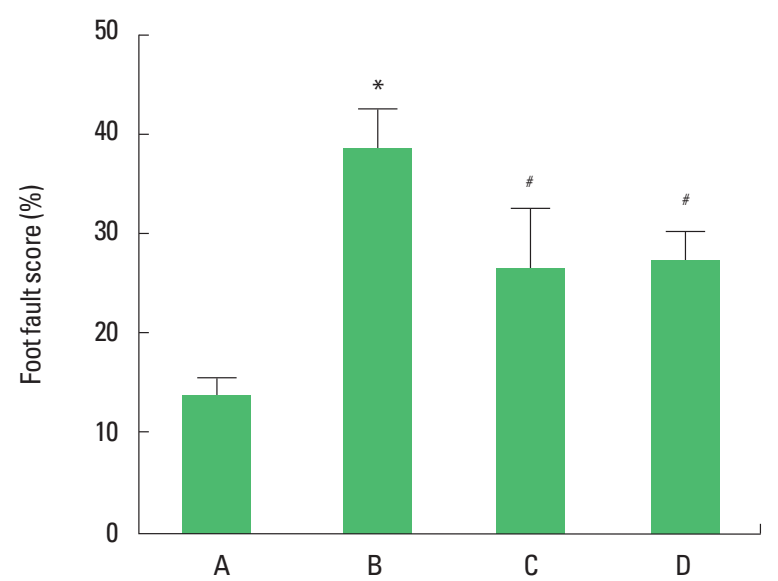

Fig. 3. Effects of treadmill exercise and wheel exercise on walking ability in foot fault test. A, sham-operation group; B, brain inflammation-induced group; $\mathrm{C}$, brain inflammation-induced group and treadmill exercise group; $\mathrm{D}$, brain inflammation-induced and wheel exercise group. ${ }^{*} P<0.05$ compared with sham-operation group. ${ }^{*} P<0.05$ compared with brain inflammation-induced group.

\section{$\mathrm{Bcl}-2$ and Bax expressions in the motor cortex}

To verify the apoptosis induced by brain inflammation, we ascertained relative expressions of Bax and Bcl-2 (Fig. 4). The present results showed that brain inflammation enhanced the expression of $\mathrm{Bax}(P<0.05)$ and enfeebled the expression of $\mathrm{Bcl}-2$ $(P<0.05)$. Therefore, brain inflammation enhanced the ratio of Bax to Bcl-2. Treadmill exercise and wheel exercise suppressed the expression of $\mathrm{Bax}$ in the brain inflammation-induced rats $(P<0.05)$, resulting in decrease of Bax to Bcl-2 ratio $(P<0.05)$. Treadmill exercise and wheel exercise exerted similar inhibitory effect on Bax expression.

\section{TUNEL-positive cells in the motor cortex}

Photomicrographs of TUNEL-positive cells in the motor cortex are presented in Fig. 5. The present results showed that brain inflammation enhanced the number of the TUNEL-positive cells $(P<0.05)$, whereas, treadmill exercise and wheel exercise suppressed this number of the TUNEL-positive cells in the brain inflammation-induced rats $(P<0.05)$. Treadmill exercise and wheel exercise exerted similar inhibitory effect on the number of the TUNEL-positive cells.

\section{Caspase- 3 expression in the motor cortex}

Photomicrographs of caspase-3-positive cells in the motor cortex are presented in Fig. 6. The present results showed that brain

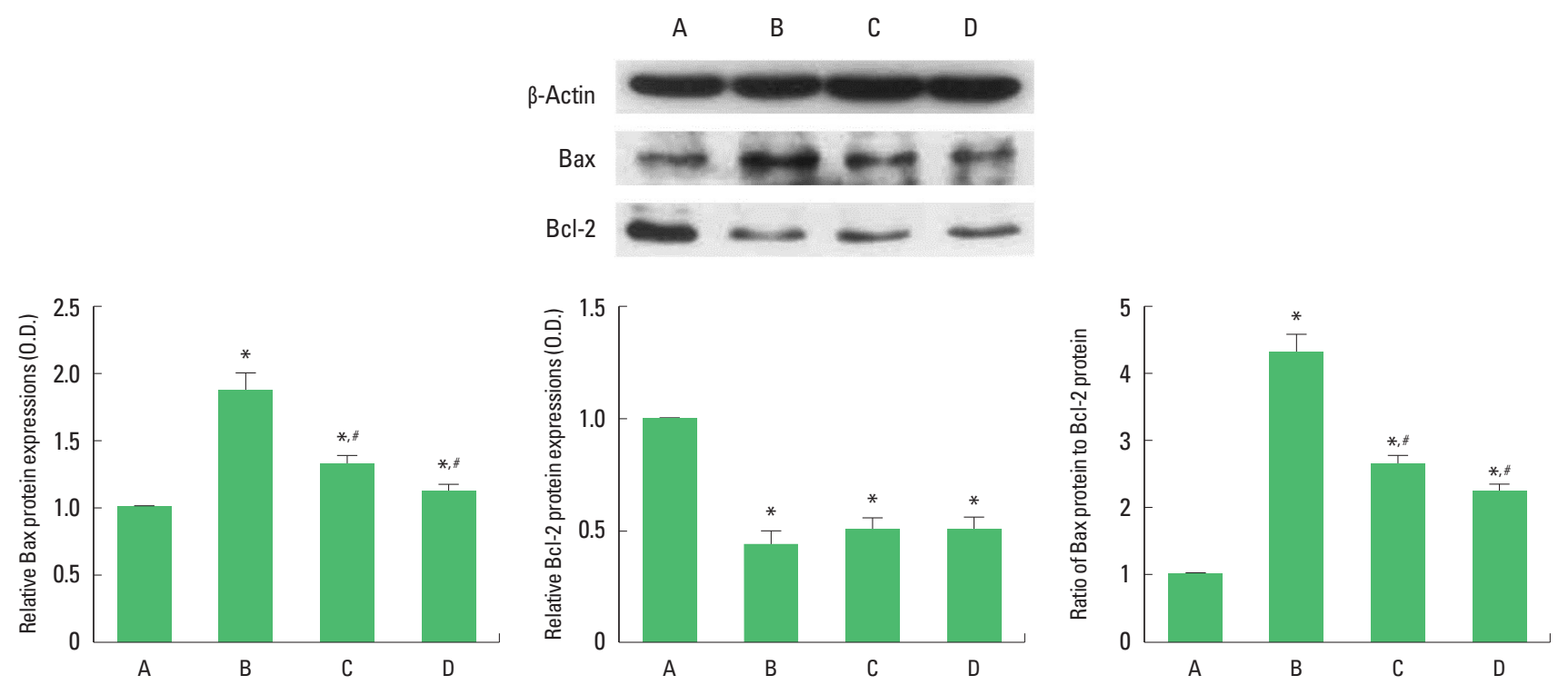

Fig. 4. Effects of treadmill exercise and wheel exercise on expressions of Bax and Bcl-2 in the motor cortex. Upper panel: Presentative expression of Bax and Bcl-2. Lower panel: Relative expression of Bax and Bcl-2. A, sham-operation group; B, brain inflammation-induced group; C, brain inflammation-induced group and treadmill exercise group; $\mathrm{D}$, brain inflammation-induced and wheel exercise group. ${ }^{*} P<0.05$ compared with sham-operation group. ${ }^{\sharp} P<0.05$ compared with brain inflammation-induced group. 

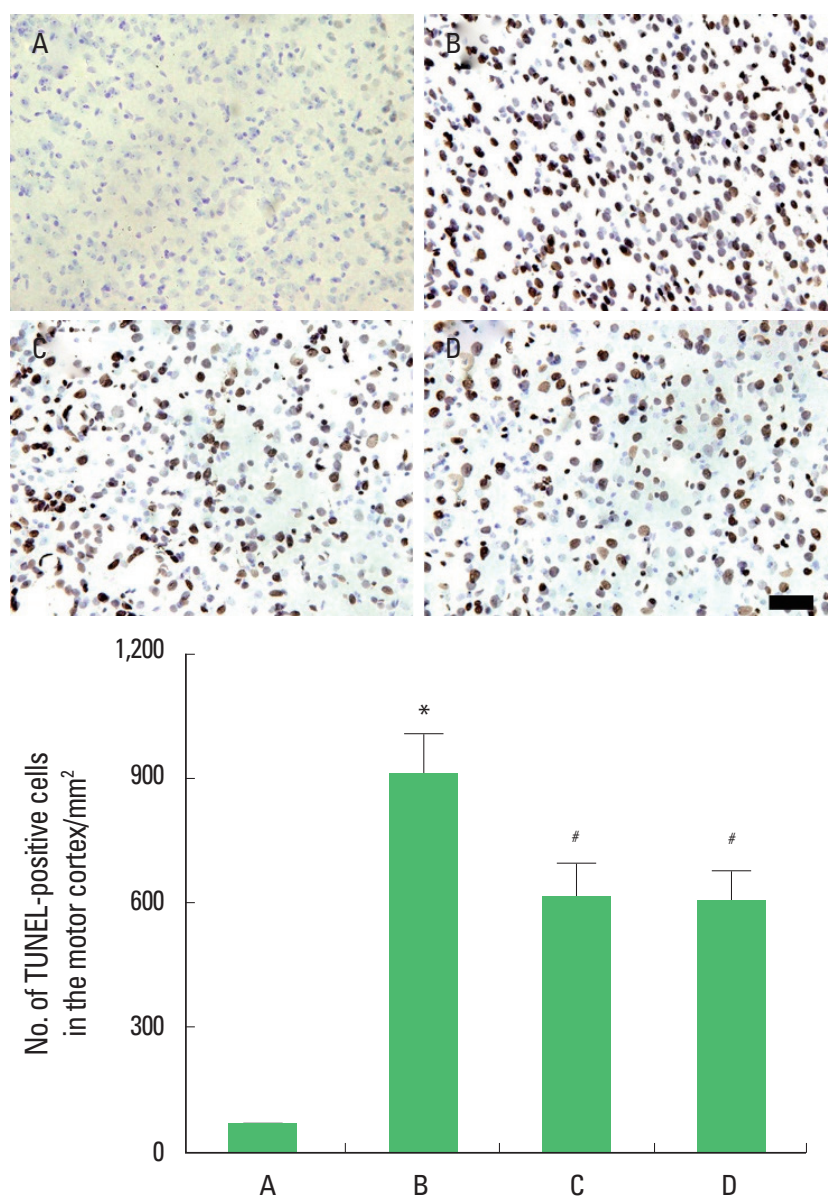

Fig. 5. Effects of treadmill exercise and wheel exercise on DNA fragmentation in the motor cortex. Upper panel: Photomicrographs of terminal deoxynucleotidyl transferase-mediated dUTP nick end labeling (TUNEL)-positive cells in the motor cortex. The scale bar represents $100 \mu \mathrm{m}$. Lower panel: Number of TUNEL-positive cells in each group. A, sham-operation group; $B$, brain inflammation-induced group; $\mathrm{C}$, brain inflammation-induced group and treadmill exercise group; $D$, brain inflammation-induced and wheel exercise group. ${ }^{*} P<0.05$ compared with sham-operation group. ${ }^{\sharp} P<0.05$ compared with brain inflammation-induced group.

inflammation enhanced caspase- 3 expression $(P<0.05)$, whereas, treadmill exercise and wheel exercise suppressed this caspase- 3 expression in the brain inflammation-induced rats $(P<0.05)$. Treadmill exercise and wheel exercise exerted similar inhibitory effect on the caspase-3 expression.

\section{DISCUSSION}

Dysfunction of motor ability following neuroinflammation causes dysequilibrium, dysbasia, and paralysis (Hauss-Wegrzyniak et al., 2000). LPS-induced pro-inflammatory factors enter the brain through the areas with incomplete BBB (Banks and Erick-
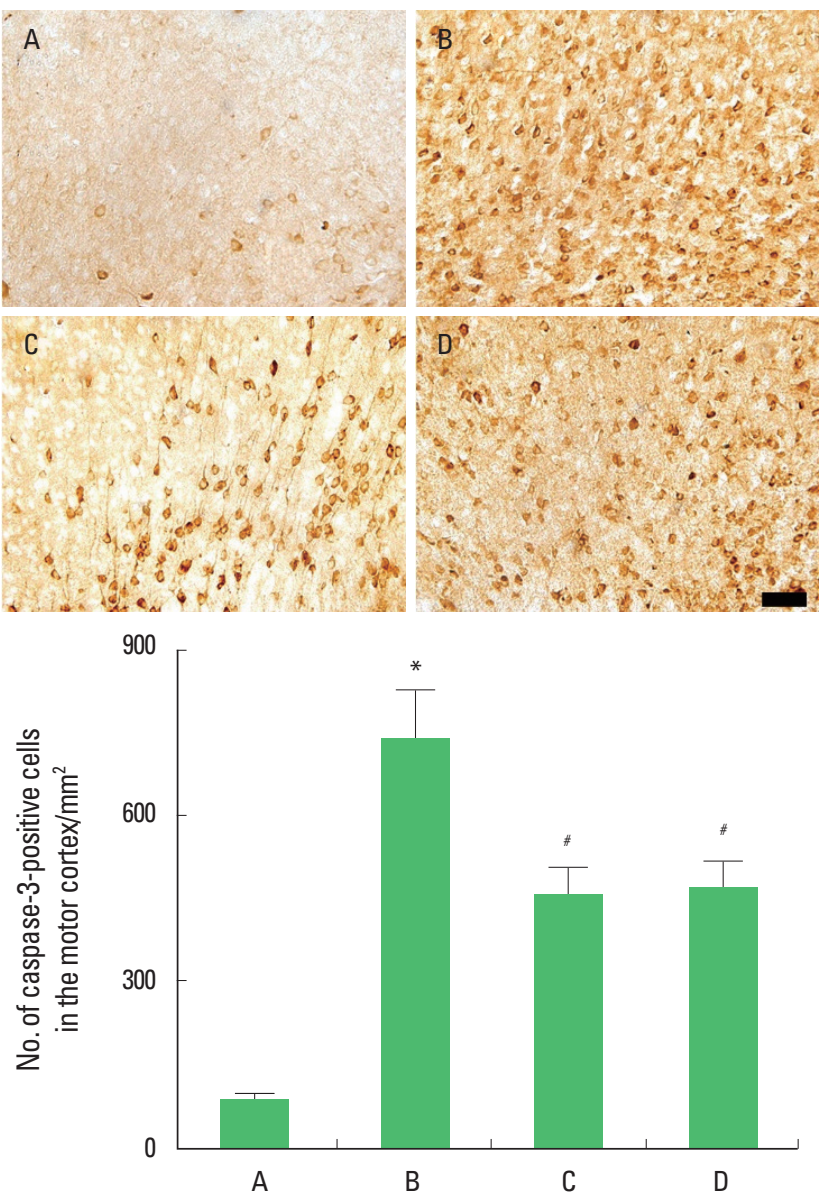

Fig. 6. Effects of treadmill exercise and wheel exercise on caspase-3 expression in the motor cortex. Upper panel: Photomicrographs of caspase-3-positive cells in the motor cortex. The scale bar represents $100 \mu \mathrm{m}$. Lower panel: Number of caspase-3-positive cells in each group. A, sham-operation group; $B$, brain inflammation-induced group; $C$, brain inflammation-induced group and treadmill exercise group; $\mathrm{D}$, brain inflammation-induced and wheel exercise group. ${ }^{*} P<0.05$ compared with sham-operation group. ${ }^{*} P<0.05$ compared with brain inflammation-induced group.

son, 2010). Many studies showed the close relation between brain inflammation and motor ability deficits (Belmadani et al., 2006; Xu et al., 2007).

In the present results, the latency in the rotarod test and descending time in the vertical pole test were shortened by induction of brain inflammation. In addition, the foot fault score in the foot fault test was increased following induction of brain inflammation. These results revealed that brain inflammation-induction incapacitated motor ability, such as balance, coordination, and walking function.

During the process of neuroinflammation, apoptosis-regulatory proteins are repeatedly implicated in the susceptibility of neurons 
to cell death (Zipp et al., 2002). Ultrastructural analysis showed the three self-destructive processes in the cerebral ventricles following LPS administration: apoptosis, autophagy, and necrosis (Czapski et al., 2010). Especially, apoptosis appears to play an important role in neuronal cell death by LPS-induced brain inflammation (Zarifkar et al., 2010). LPS induces phosphorylation on apoptotic genes such as mitogen-activated protein kinase, p38, and p58, triggering cellular deterioration (Nolan et al., 2003). LPS-induced increase of TUNEL staining and capase-3 expression caused degenerative change in the motor cortex (Miklossy, 2008).

In the present results, LPS injection into the intraventricular enhanced the number of TUNEL-positive cells and caspase- 3 exprression in the motor cortex, showing that LPS induced apoptosis in the motor cortex.

The Bcl-2 family, including Bcl-2 and Bcl-xL, plays an important role in the regulation of apoptosis in the nervous system (Akhtar et al., 2004; Park et al., 2017). Bcl-2 can inhibit apoptosis by preventing the release of cytochrome $c$ from mitochondria. However, $\mathrm{Bcl}-2$ and $\mathrm{Bcl}-\mathrm{xL}$ form heterodimers with the main pro-apoptotic member Bax and can be incapacitated in their protective function (Kuwana and Newmeyer, 2003). Thus, the Bcl-2/ Bax balance has been used as the crucial factor determining apoptosis.

In the present results, brain inflammation increased Bax level and decreased Bcl-2 level. These results increased Bax to Bcl-2 ratio, indicating that brain inflammation initiated apoptotic cell death in the motor cortex.

Physical exercise prevented motor functional impairment due to dysbasia and dysequilibrium by brain inflammation (Nair and Taly, 2002). Dysfunctions of motor ability following brain injury was improved by regular physical exercise (Globas et al., 2009).

In the present results, latency in the rota-rod test and descending time in the vertical pole test were shorted by induction of brain inflammation, and foot fault score in the foot fault test was increased by induction of brain inflammation. In contrast, latency in the rota-rod test and descending time in the vertical pole test was lengthened by treadmill exercise and wheel exercise. Foot fault score in the foot fault test was decreased by treadmill exercise and wheel exercise.

Treadmill exercise prevented neuronal loss and functional impairments due to excitotoxic damage, cytokine dysfunction, and brain insults (Fehrenbach and Schneider, 2006; Parachikova et al., 2008). Physical exercise prevented apoptotic cell death in the cerebral cortex and hippocampus and facilitated recovery from brain inflammation (Lucassen et al., 2010). Long-term exercise in- creased the levels of anti-inflammatory factors in the blood, internal organs, and brain (Aoi et al., 2010; Curry et al., 2010; Leem et al., 2011).

In the present results, treadmill exercise and wheel exercise suppressed brain inflammation-induced TUNEL-positive cells and caspase- 3 expression in the motor cortex, showing that treadmill exercise and wheel exercise ameliorated LPS-induced apoptosis in the motor cortex. Moreover, treadmill exercise and wheel exercise suppressed Bax expression in the motor cortex, resulting in decreased Bax to Bcl-2 ratio. From these results, it can be suggested that treadmill exercise and wheel exercise have ameliorating effect on brain inflammation-induced apoptotic neuronal cell death in motor cortex.

This study showed that treadmill exercise and wheel exercise alleviated brain inflammation-induced motor impairments by suppressing apoptotic neuronal cell death in the motor cortex. These effects of treadmill exercise and wheel exercise were similarly appeared.

\section{CONFLICT OF INTEREST}

No potential conflict of interest relevant to this article was reported.

\section{REFERENCES}

Akhtar RS, Ness JM, Roth KA. Bcl-2 family regulation of neuronal development and neurodegeneration. Biochim Biophys Acta 2004;1644:189203.

Aoi W, Naito Y, Takagi T, Kokura S, Mizushima K, Takanami Y, Kawai Y, Tanimura Y, Hung LP, Koyama R, Ichikawa H, Yoshikawa T. Regular exercise reduces colon tumorigenesis associated with suppression of iNOS. Biochem Biophys Res Commun 2010;399:14-19.

Banks WA, Erickson MA. The blood-brain barrier and immune function and dysfunction. Neurobiol Dis 2010;37:26-32.

Belmadani A, Tran PB, Ren D, Miller RJ. Chemokines regulate the migration of neural progenitors to sites of neuroinflammation. J Neurosci 2006;26:3182-3191.

Cadet P, Zhu W, Mantione K, Rymer M, Dardik I, Reisman S, Hagberg S, Stefano GB. Cyclic exercise induces anti-inflammatory signal molecule increases in the plasma of Parkinson's patients. Int J Mol Med 2003;12:485-492.

Cohen GM. Caspases: the executioners of apoptosis. Biochem J 1997;326 (Pt 1):1-16.

Curry A, Guo M, Patel R, Liebelt B, Sprague S, Lai Q, Zwagerman N, Cao 
FX, Jimenez D, Ding Y. Exercise pre-conditioning reduces brain inflammation in stroke via tumor necrosis factor- $\alpha$, extracellular signal-regulated kinase $1 / 2$ and matrix metalloproteinase- 9 activity. Neurol Res 2010;32:756-762.

Czapski GA, Cakala M, Chalimoniuk M, Gajkowska B, Strosznajder JB. Role of nitric oxide in the brain during lipopolysaccharide-evoked systemic inflammation. J Neurosci Res 2007;85:1694-1703.

Czapski GA, Gajkowska B, Strosznajder JB. Systemic administration of lipopolysaccharide induces molecular and morphological alterations in the hippocampus. Brain Res 2010;1356:85-94.

Emerit J, Edeas M, Bricaire F. Neurodegenerative diseases and oxidative stress. Biomed Pharmacother 2004;58:39-46.

Fehrenbach E, Schneider ME. Trauma-induced systemic inflammatory response versus exercise-induced immunomodulatory effects. Sports Med 2006;36:373-384.

Funk JA, Gohlke J, Kraft AD, McPherson CA, Collins JB, Jean Harry G. Voluntary exercise protects hippocampal neurons from trimethyltin injury: possible role of interleukin-6 to modulate tumor necrosis factor receptor-mediated neurotoxicity. Brain Behav Immun 2011;25:10631077.

Gavrieli Y, Sherman Y, Ben-Sasson SA. Identification of programmed cell death in situ via specific labeling of nuclear DNA fragmentation. J Cell Biol 1992;119:493-501.

Globas C, Macko RF, Luft AR. Role of walking-exercise therapy after stroke. Expert Rev Cardiovasc Ther 2009;7:905-910.

Hauss-Wegrzyniak B, Vannucchi MG, Wenk GL. Behavioral and ultrastructural changes induced by chronic neuroinflammation in young rats. Brain Res 2000;859:157-166.

Jacewicz M, Czapski GA, Katkowska I, Strosznajder RP. Systemic administration of lipopolysaccharide impairs glutathione redox state and object recognition in male mice. The effect of PARP-1 inhibitor. Folia Neuropathol 2009;47:321-328.

Johnson EM Jr, Greenlund LJ, Akins PT, Hsu CY. Neuronal apoptosis: current understanding of molecular mechanisms and potential role in ischemic brain injury. J Neurotrauma 1995;12:843-852.

Jung SY, Kim DY. Treadmill exercise improves motor and memory functions in cerebral palsy rats through activation of PI3K-Akt pathway. J Exerc Rehabil 2017 30;13:136-142.

Kim SE, Ko IG, Shin MS, Kim CJ, Jin BK, Hong HP, Jee YS. Treadmill exercise and wheel exercise enhance expressions of neutrophic factors in the hippocampus of lipopolysaccharide-injected rats. Neurosci Lett 2013;538:54-59.

Kuwana T, Newmeyer DD. Bcl-2-family proteins and the role of mitochondria in apoptosis. Curr Opin Cell Biol 2003;15:691-699.

Lee MH, Kim H, Kim SS, Lee TH, Lim BV, Chang HK, Jang MH, Shin
MC, Shin MS, Kim CJ. Treadmill exercise suppresses ischemia-induced increment in apoptosis and cell proliferation in hippocampal dentate gyrus of gerbils. Life Sci 2003;73:2455-2465.

Leem YH, Lee YI, Son HJ, Lee SH. Chronic exercise ameliorates the neuroinflammation in mice carrying NSE/htau23. Biochem Biophys Res Commun 2011;406:359-365.

Lucassen PJ, Meerlo P, Naylor AS, van Dam AM, Dayer AG, Fuchs E, Oomen CA, Czéh B. Regulation of adult neurogenesis by stress, sleep disruption, exercise and inflammation: implications for depression and antidepressant action. Eur Neuropsychopharmacol 2010;20:1-17.

Miklossy J. Chronic inflammation and amyloidogenesis in Alzheimer's disease: role of Spirochetes. J Alzheimers Dis 2008;13:381-391.

Nair KP, Taly AB. Stroke rehabilitation: traditional and modern approaches. Neurol India 2002;50:85-93.

Nichol KE, Poon WW, Parachikova AI, Cribbs DH, Glabe CG, Cotman CW. Exercise alters the immune profile in Tg2576 Alzheimer mice toward a response coincident with improved cognitive performance and decreased amyloid. J Neuroinflammation 2008;5:13.

Nolan Y, Vereker E, Lynch AM, Lynch MA. Evidence that lipopolysaccharide-induced cell death is mediated by accumulation of reactive oxygen species and activation of p38 in rat cortex and hippocampus. Exp Neurol 2003;184:794-804.

Parachikova A, Nichol KE, Cotman CW. Short-term exercise in aged Tg2576 mice alters neuroinflammation and improves cognition. Neurobiol Dis 2008;30:121-129.

Park JH, Kim SE, Jin JJ, Choi HS, Kim CJ, Ko IG. Pentoxifylline alleviates perinatal hypoxic-ischemia-induced short-term memory impairment by suppressing apoptosis in the hippocampus of rat pups. Int Neurourol J 2016;20:107-113.

Park JH, Ko IG, Kim SE, Jin JJ, Hwang L, Kim CJ, Yoon SH, Hong J, Chung JY, Lee DW. Dexmedetomidine oral mucosa patch for sedation suppresses apoptosis in hippocampus of normal rats. Int Neurourol J 2017;21(Suppl 1):S39-47.

Petersen AM, Pedersen BK. The anti-inflammatory effect of exercise. J Appl Physiol (1985) 2005;98:1154-1162.

Rodriguez P, Zhao J, Milman B, Tiwari YV, Duong TQ. Methylene blue and normobaric hyperoxia combination therapy in experimental ischemic stroke. Brain Behav 2016;6:e00478.

Shin MS, Park HK, Kim TW, Ji ES, Lee JM, Choi HS, Kim MY, Kim YP. Neuroprotective effects of bone marrow stromal cell transplantation in combination with treadmill exercise following traumatic brain injury. Int Neurourol J 2016;20(Suppl 1):S49-56.

Strosznajder RP, Gadamski R, Czapski GA, Jesko H, Strosznajder JB. Poly (ADP-ribose) polymerase during reperfusion after transient forebrain ischemia: its role in brain edema and cell death. J Mol Neurosci 2003; 
20:61-72.

Tong L, Shen H, Perreau VM, Balazs R, Cotman CW. Effects of exercise on gene-expression profile in the rat hippocampus. Neurobiol Dis 2001; 8:1046-1056

Trendelenburg G. Acute neurodegeneration and the inflammasome: central processor for danger signals and the inflammatory response? J Cereb Blood Flow Metab 2008;28:867-881.

Upadhyay D, Panduri V, Ghio A, Kamp DW. Particulate matter induces alveolar epithelial cell DNA damage and apoptosis: role of free radicals and the mitochondria. Am J Respir Cell Mol Biol 2003;29:180-187.

Winkelman C. Inactivity and inflammation: selected cytokines as biologic mediators in muscle dysfunction during critical illness. AACN Clin Issues 2004;15:74-82.

Woodle ES, Kulkarni S. Programmed cell death. Transplantation 1998;66: 681-691.
Xu F, Grande AM, Robinson JK, Previti ML, Vasek M, Davis J, Van Nostrand WE. Early-onset subicular microvascular amyloid and neuroinflammation correlate with behavioral deficits in vasculotropic mutant amyloid beta-protein precursor transgenic mice. Neuroscience 2007; 146:98-107.

Yun HS, Park MS, Ji ES, Kim TW, Ko IG, Kim HB, Kim H. Treadmill exercise ameliorates symptoms of attention deficit/hyperactivity disorder through reducing Purkinje cell loss and astrocytic reaction in spontaneous hypertensive rats. J Exerc Rehabil 2014;10:22-30.

Zarifkar A, Choopani S, Ghasemi R, Naghdi N, Maghsoudi AH, Maghsoudi N, Rastegar K, Moosavi M. Agmatine prevents LPS-induced spatial memory impairment and hippocampal apoptosis. Eur J Pharmacol 2010;634:84-88.

Zipp F, Aktas O, Lünemann JD. The role of apoptosis in neuroinflammation. Ernst Schering Res Found Workshop 2002;39:213-229. 